\title{
Detection of Foot-and-Mouth
} Disease Virus in the Absence of Clinical Disease in Cattle and Buffalo in South East Asia

Kelly Buckle ${ }^{1 *}$, Rudolfo Bueno ${ }^{1}$, Andrew McFadden ${ }^{1}$, Mary van Andel ${ }^{2}$, Richard Spence ${ }^{1}$, Carolyn Hamill ${ }^{1}$, Wendi Roe ${ }^{3}$, Emilie Vallee ${ }^{3}$, Fernanda Castillo-Alcala ${ }^{3}$, Ronel Abila ${ }^{4}$, Blesilda Verin ${ }^{4}$, Bolortuya Purevsuren ${ }^{4}$, Ashish Sutar ${ }^{4}$, Htun Htun Win ${ }^{5}$, Myo Thiha ${ }^{5}$, Khin Ohnmar Lwin ${ }^{5}$, Syseng Khounsy ${ }^{6}$, Sengxay Phonthasy ${ }^{6}$, Viliddeth Souriya ${ }^{6}$, Chattouphone Keokhamphet ${ }^{6}$, Jonathan Arzt ${ }^{7}$, Anna Ludi $^{8}$ and Valérie Mioulet ${ }^{8}$

\section{OPEN ACCESS}

Edited by:

Alejandra Victoria Capozzo, Consejo Nacional de Investigaciones

Científicas y Técnicas (CONICET), Argentina

Reviewed by: James A. Roth, lowa State University, United States Brianna R. Beechler, Oregon State University, United States

*Correspondence: Kelly Buckle kelly.buckle@mpi.govt.nz

Specialty section: This article was submitted to Veterinary Epidemiology and Economics,

a section of the journal Frontiers in Veterinary Science

Received: 06 April 2021 Accepted: 22 June 2021 Published: 23 July 2021

Citation: Buckle K, Bueno R, McFadden A, van Andel M, Spence R, Hamill C, Roe W, Vallee E, Castillo-Alcala $F$, Abila $R$, Verin $B$, Purevsuren $B$, Sutar $A$, Win HH, Thiha M, Lwin KO, Khounsy S, Phonthasy S, Souriya $V$, Keokhamphet C, Arzt J, Ludi A and Mioulet V (2021) Detection of Foot-and-Mouth Disease Virus in the Absence of Clinical Disease in Cattle and Buffalo in South East Asia.

Front. Vet. Sci. 8:691308 doi: $10.3389 /$ fvets.2021.691308

\begin{abstract}
${ }^{1}$ Ministry for Primary Industries, Biosecurity New Zealand, Diagnostic and Surveillance Services Directorate, Wallaceville, New Zealand, ${ }^{2}$ Ministry for Primary Industries, Office of the Chief Departmental Scientist, Wellington, New Zealand, ${ }^{3}$ School of Veterinary Science, Massey University, Palmerston North, New Zealand, ${ }^{4}$ OIE Sub-regional Representation for South East Asia, Bangkok, Thailand, ${ }^{5}$ Livestock Breeding and Veterinary Department, Nay Pyi Taw, Myanmar, ${ }^{6}$ Department of Livestock and Fisheries, Vientiane, Laos, ${ }^{7}$ Foreign Animal Disease Research Unit, Agricultural Research Service, United States Department of Agriculture, New York, NY, United States, ${ }^{8}$ The Pirbright Institute, Woking, United Kingdom
\end{abstract}

Foot-and-mouth disease virus (FMDV) is widespread throughout much of the world, including parts of South East Asia. Surveillance is often limited in endemic areas, relying predominantly on passive outbreak reporting. As part of the World Organisation for Animal Health (OIE)'s South East Asia and China Foot-and-Mouth Disease Project (SEACFMD), field sampling was performed to help understand evidence of widespread virus exposure observed in previous studies. Serum and dry mucosal swabs were collected to evaluate the presence of FMDV RNA on the nasal, oral, and dorsal nasopharyngeal mucosal surfaces of 262 healthy cattle $(n=84$ in Laos; $n=125$ in Myanmar) and buffalo ( $n=48$ in Laos; $n=5$ in Myanmar) immediately following slaughter in three slaughterhouses. Swabs and serum were tested by the OIE/FAO World Reference Laboratory for foot-and-mouth disease (WRLFMD) using pan-serotypic real-time reverse transcription-PCR (rRT-PCR) and serum was evaluated using the FMD PrioCHECK non-structural protein (NSP) ELISA. In total, $7.3 \%$ of animals had detectable FMDV RNA in one or more of the three sites including $5.3 \%$ of nasopharyngeal swabs, $2.3 \%$ of oral swabs, and $1.5 \%$ of nasal swabs. No FMDV RNA was detected in serum. Overall, $37.8 \%$ of animals were positive for NSP antibodies, indicating likely past natural exposure to FMDV. Results were comparable for Laos and Myanmar, and for both cattle and buffalo, and were not significantly different between age groups. Detectable FMDV RNA present on the oral and nasal mucosa of clinically-healthy large ruminants in Laos and Myanmar demonstrates the importance of sampling asymptomatic animals as part of surveillance, and may indicate that subclinical infection plays a role in the epidemiology of FMD in these countries.

Keywords: abattoirs, surveillance, buffaloes, cattle, foot-and-mouth disease, foot-and-mouth disease virus, reverse transcriptase polymerase chain reaction 


\section{INTRODUCTION}

Foot-and-mouth disease virus (FMDV) is a contagious Picornavirus of cloven-hoofed ungulates (Artiodactyla), present in approximately two-thirds of the world's countries. In these countries, it acts as a significant barrier to trade $(1,2)$. Parameters of acute FMD infection in naïve cattle are welldefined, and continue to be refined by research $(3,4)$. In contrast, the subclinical cycles of FMD in the approximately 128 countries where the virus circulates are less-well documented, and the characteristic, "fulminant" herd-wide disease may be observed or reported inconsistently in endemic regions compared to what is documented in epidemic contexts $(5,6)$. Almost 50 years ago, Anderson et al. (7) wrote that "the occurrence of clinical outbreaks does not necessarily give a true assessment of the amount of virus in the environment as subclinical or in apparent infection could occur, particularly in partially immune cattle." Much uncertainty remains about how FMD manifests in endemically-infected herds, and the various states by which subclinical infection exists (8).

The majority of naïve cattle exposed to FMDV will become infected through exposure of the mucosa of the upper respiratory tract, and will develop viraemia and lesions in a wellcharacterised pattern (9). Antibodies are a useful indicator of natural exposure, and may be partially cross-protective to future infection from other serovars (10). Cattle with viral infection past 28 days are defined as chronic carriers, with virus most commonly persisting in the nasopharyngeal mucosa $(8,11)$. In live chronic carriers, the probang technique, using a metal cup which is used to collect oropharyngeal fluid and mucosal cells from the pharyngeal region, provides the most useful sample of the area of viral persistence, allowing for molecular detection and virus isolation $(8,12)$. Scraping the same area with a cuvette at slaughter also yields virus (7).

The chronic carrier state is just one of several sub-clinical and immunological states of FMDV infection. It is a focus of research for FMD-free countries, largely because of its importance for declaration of freedom implications following an incursion. The other sub-clinical states of large ruminants are important for understanding the epidemiology of FMDV in endemic regions. These states include: (1) a pre-clinical (incubation phase) state between exposure and lesion development and (2) neoteric sub-clinical infection in which breed or speciesassociated host-adaptation precludes clinical signs of FMD (13, 14). Immunity and seropositivity may result from (1) vaccination with an appropriate serotype-specific vaccine and (2) an immune state resulting from previous exposure or maternal transfer of antibodies (strongest against the original infecting serotype).

Knowledge of in-country FMD epidemiology forms one of the major requirements for countries participating in the Food and Agriculture Organisation of the United Nations (FAO) and the World Organisation for Animal Health (OIE)'s Progressive Control Programme for FMD (PCP-FMD), which provides a benchmarking guide to countries wishing to progress toward FMD freedom (15). Protective natural immunity is not a factor addressed in FMD research, despite the high seroprevalence in some regions and the possible role this "herd immunity" plays in suppressing disease outbreaks in the face of circulating FMDV. In non-vaccinated populations of large ruminants, documented seroprevalence ranges from 19 to $71 \%$ in Africa (16-18), and between 18 and 51\% in Asia (19-21).

Control of FMD has been identified as a priority for the livestock production sectors in Myanmar and Lao PDR, due to their perceived role in regional transmission of FMD due to cattle movement (22). Previous studies undertaken in these countries as part of the PCP-FMD demonstrated widespread exposure of cattle, with up to $56 \%$ of villages in central Myanmar demonstrating serological evidence of FMDV exposure (5), 51\% of large ruminants at a Laos slaughterhouse testing positive on serology (20) and the circulation of multiple strains of FMDV (types O, A, and Asia 1) $(23,24)$. Seropositivity is greater than predicted by either formal outbreak reporting (25) or village headman observations (5). This suggests that research is needed to better define the role played by subclinical animals in FMDV transmission in Myanmar and other FMDV-endemic countries with similar husbandry and ecological conditions.

As part of addressing this research need, the present study evaluated whether FMDV is detectable on the mucosal surfaces of healthy cattle and buffalo in Laos and Myanmar, with samples taken at slaughter. The results of this study may help better understand the parameters of subclinical epidemiology of FMDV in the Southeast Asian region.

\section{MATERIALS AND METHODS}

Slaughterhouse (SH) sites: sampling occurred at Dongdou SH and Nangduang SH (Vientiane, Laos) during May and June, 2019; and at Mandalay City SH, Mandalay, Myanmar during July and August, 2019 (Figure 1). Animal contact at the slaughterhouses varied-at Dongdou animals were gathered in a chute up to $12 \mathrm{~h}$ prior to slaughter, and secured to a railing with a headrope. At the other slaughterhouses, animals typically arrived in small groups by truck up to $24 \mathrm{~h}$ prior to slaughter and were tethered by a headrope to trucks or within the slaughterhouse, or kept in stalls with animals from one trader together until the time of slaughter. Animals from one trader could represent multiple original villages, districts or townships of origin. Animals were brought by traders to the slaughterhouse in groups, collected from different villages and transported together. For the Myanmar slaughterhouse, animals from 16 traders were sampled over five nights. In Laos, all animals tested at Dongdou were supplied by one trader, but at Nangduang (a more traditional slaughterhouse), animals were supplied by 10 traders over three nights.

Study population: Apparently healthy cattle and buffalo bound for human consumption were sampled opportunistically postmortem. Complete samples were obtained from 132 animals ( 84 cattle and 48 buffalo) in Laos, and 130 animals (125 cattle and 5 buffalo) in Myanmar. Animals were observed at a distance prior to slaughter, and no clinical disease was noted.

Samples: A sample set including serum and swabs from three sites (nasal, oral, and dorsal nasopharyngeal mucosae) were collected from each animal immediately after slaughter. Whole 


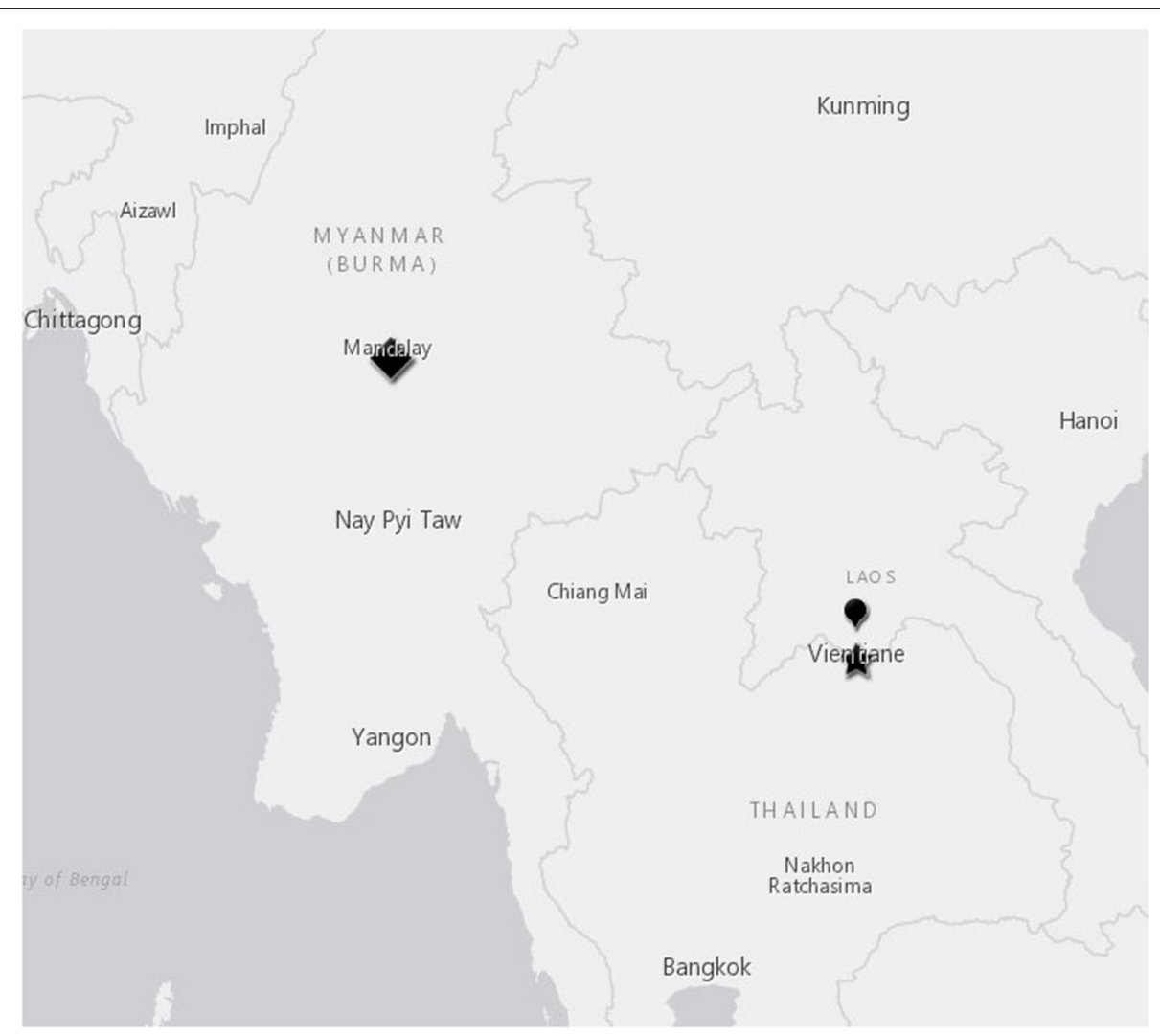

FIGURE 1 | Slaughterhouse locations in Mandalay, Myanmar and Vientiane, Laos. Mandalay slaughterhouse, diamond symbol; Dongdou slaughterhouse, star symbol; Nangduang slaughterhouse, balloon symbol.

blood was collected in $10 \mathrm{~mL}$ red-top (plain) Vacutainer tubes (Becton, Dickinson and Company, Franklin Lakes, New Jersey, USA) following severing of the jugular vein as part of the normal slaughter process. Tubes were either centrifuged at $1,500 \times g$ for $3 \mathrm{~min}$, or left to clot within $12 \mathrm{~h}$ of collection. Serum $(1 \mathrm{~mL})$ was then collected into a $1.5 \mathrm{~mL}$ screw cap tube (Sarstedt) and frozen at $-80^{\circ} \mathrm{C}$ until processing. Plain dry rayon Copan ${ }^{\mathrm{TM}}$ swabs (Copan Diagnostics Inc., Murrieta, California USA) were collected from the above-mentioned sites during the slaughter process, were immediately inserted into a cryovial containing $1.0 \mathrm{~mL}$ of DNA/RNA Shield ${ }^{\mathrm{TM}}$ (Zymo Research), and were kept chilled on ice packs for between three to $12 \mathrm{~h}$ until arrival at the local laboratory where they were frozen at $-80^{\circ} \mathrm{C}$ for transport to the World Reference Laboratory for FMD at the Pirbright Institute (Ash Road, Surrey, UK).

Swabs were collected in the following manner: Oral swabs were rubbed for approximately three seconds on the hard palate, buccal surfaces, and tongue as possible given the position of the animal, and were inserted up to the length of the $15 \mathrm{~cm}$ swab; nasal swabs were rubbed on all inside surfaces of both nostrils for 1-2 s each, with the swab inserted up to the length of the $15 \mathrm{~cm}$ swab into the nasal openings; pharyngeal samples prioritised sampling of the dorsal pharyngeal mucosa, the site of optimal experimental FMDV retrieval for persistentlyinfected animals (26) and involved insertion of the swab from a caudal direction through the oesophagus, with blind manual guidance to the dorsal nasopharyngeal mucosa, which was rubbed vigorously for 3-5 s. During initial sampling, dissection of a buffalo head confirmed that palpation of landmarks allowed sampling of the target mucosal surface. Where ruminal contamination was present, heads were pre-washed with water from a hose or bucket to minimise contamination of swabs. During collection, field staff employed frequent changing of gloves to prevent cross-contamination. Environmental control samples were collected each 10-15 carcasses by waving swabs through air adjacent to carcass collection sites (air controls) and by immersing swabs in local hose or trough water (water controls).

Data collected at sampling: Prior to slaughter, oral and nasal lesions and any signs of lameness were assessed and recorded. Animal species, age, and sex were collected from traders at the time of sampling. At the time of sampling, the external nares and rostral oral cavity were observed for the presence of gross lesions including vesicles, erosions or swellings.

Laboratory assays: The frozen serum and swab samples were maintained at $-80^{\circ} \mathrm{C}$ at the National Animal Health Laboratory of the country of origin, then transported to Pirbright Institute on dry ice (Ash Road, Surrey, UK). Serum was evaluated for FMDV non-structural proteins (NSPs) using the FMD PrioCHECK NSP ELISA as per 
kit instructions with the exception that two wells were used per sample. Swabs were evaluated for the presence of FMDV RNA by the pan-serotypic 3D one-step real-time reverse transcription-PCR (RT-qPCR) (27). RT-PCR values were determined to be positive if the cycle threshold (CT) value was under 40 .

Analysis: analyses were performed in $\mathrm{R}$ ( $\mathrm{R}$ version 4.0.0 (2020-04-24) Copyright (C) 2020 The $\mathrm{R}$ Foundation for Statistical Computing) (28).

\section{RESULTS}

Detectable FMDV RNA was present on the oral and nasal mucosa of a small but consistent number of cattle and buffalo from both countries and all slaughterhouses. This included 3.4\% (9/262, 95\% CI 1.58-6.42\%) of all animals which had detectable FMDV RNA on oral and/or nasal swabs. When pharyngeal swabs were added to the oral and nasal swabs, $7.3 \%(19 / 262$, 95\% CI $4.42-11.09 \%)$ of all animals in both countries had detectable FMDV RNA on at least one swab (Table 1), including $10.4 \%(5 / 48,95 \%$ CI $3.47-22.66 \%)$ buffalo and $6.0 \%(5 / 84,95 \%$ CI $1.96-13.34 \%)$ cattle in Laos, and $0 \%(0 / 5,95 \%$ CI $0.00-$ $52.18 \%)$ buffalo and $7.2 \%$ (9/125, 95\% CI 3.34-13.23\%) cattle in Myanmar. No animals had any lesions or clinical signs consistent with FMD. In the 19 animals with positive swabs, the most common site of detection was dorsal nasopharyngeal (14/19 animals), followed by oral (6/19 animals), and then nasal (4/19 animals). There were nine animals with positive oral and/or nasal swabs $(9 / 262,3.4 \%)$. Animals with more than one positive swab included four individuals, all cattle except where indicated: a 1-year old female positive on all swabs, a 2year old female positive on both nasal and pharyngeal swabs, and a 3-year old female and 4-year old female buffalo with positive oral and pharyngeal swabs. Animals positive on at least one swab were significantly more likely to be seropositive (61.9\% seropositive, 13/21) compared with animals from the whole group $(101 / 262,38.5 \%)$ (Chi-square statistic $=4.4084$, $p=0.036)$. All environmental control swabs were negative by real time PCR.

The study group was $81 \%$ female $(212 / 262)$, and the rest were male except for one animal with unrecorded sex. Sex was not a significant factor in whether there were one or more positive swabs ( 1 positive male to 19 positive total or 5.3\%, Fisher's exact test $95 \% \mathrm{CI}(0.01-1.46), p=0.137)$. The median age was 5 years old (median $=4$ yo for Laos, 5 yo for Myanmar), and more young animals (under 24 months of age) were sampled in Laos $(n=37)$ compared to Myanmar $(n=4)$. The mean age of animals that were positive on one or more swab was 4.5 years, and age was not significantly different compared to animals that were negative on all swabs (Mann-Whitney $U$ test, $W=2545.5, p=0.4532$ ), and no significant difference was found by grouping of animals into less than and greater-than 3 years old (Chi-square test, $1.7659, p=0.1838$ ). Animals with positive RT-PCR results were spread across multiple traders and across multiple nights.

\section{DISCUSSION}

In FMD-free countries, FMDV infection typically causes fulminant disease due to the widespread lack of immunity amongst host species. There is increasing evidence, including the data presented here, that FMDV infection in endemic regions can have more subtle manifestations including various forms of subclinical infection $(21,29,30)$.

In the current study, we found that $3.4 \%$ of healthy, commercially slaughtered large ruminants from an endemic region had detectable FMDV RNA within the oral or nasal cavity. The results were similar for both Laos and Myanmar, suggesting this might be a pattern which is common throughout the region. This is supported by data from Myanmar showing that clinical FMD occurred less frequently than exposure and seroconversion (5). The FMDV 3D RT-qPCR has a diagnostic specificity of close to $100 \%$ (31) and a diagnostic sensitivity (DSe) of $97.7 \%$ (32), therefore low rates of false positivity may occur. Although false positivity could have altered the overall percent of true FMD RNA positives, this influence is likely to have been minimal. Virus isolation would be a useful next step in addressing false positivity, and should be considered in future studies.

To our knowledge, this is the first detection of FMDV by swab sampling on superficial mucosal surfaces of healthy cattle in South East Asia. Numerous studies have described subclinical detection of FMDV by probang sampling; however mucosal swab sampling has the advantage of not requiring specialised equipment and training. Previous work has shown inefficacy of FMDV detection by antemortem swabbing (33); however the current study demonstrates the utility of swab collection for surveillance in post-mortem settings. The origin of the FMDV detected is presumed to be the individual animals themselves, as no environmental contamination was detected and positive cases were scattered among locations and over several nights. Samples were taken immediately following slaughter, and site positivity was not consistently related, therefore crosscontamination between sites is assumed to have been minimal. In naïve cattle, oral and nasal shedding following experimental infection sharply declines over 21 days (34) with extinction of virus in the oral or nasal mucosa regardless of whether animals clear infection or become chronic carriers (11). The presence of FMDV RNA within the dorsal nasopharynx of chronic carriers is well-established $(11,12)$ among others. Our data suggest that small but consistent numbers of subclinical large ruminants could shed infectious FMDV particles from their oral and nasal mucosa. This may constitute an important, previouslyunreported, mechanism of persistence and circulation of FMDV in endemic countries.

The animals sampled were chosen by convenience, and nothing was known about their previous exposure to FMDV except that they originated from an FMD-endemic region. None of the animals in this study had visible scars, lesions or other clinical signs (e.g., salivation, lameness) suggestive of current or recent FMD. We used NSP ELISA positivity as an imperfect proxy for prior exposure, as a way of judging whether presence of FMDV RNA might be related to pre-clinical acute (incubation phase) FMDV infection. Vaccination with whole vaccines (which 
TABLE 1 | PCR and NSP ELISA results from healthy cattle and buffalo ( $n=262)$ tested at slaughter in Laos (Dongdou and Nongduang) and Myanmar (Mandalay).

\begin{tabular}{|c|c|c|c|c|c|c|}
\hline & & NSP ELISA Interp & NS PCR pos & OR PCR pos & DNP PCR pos & PCR pos any site \\
\hline \multirow[t]{3}{*}{ Laos } & Cattle & $38 / 84(45.2 \%)$ & $4 / 84(4.8 \%)$ & $1 / 84(1.2 \%)$ & 3/84 (3.6\%) & 5/84 (6.0\%) \\
\hline & Buffalo & $12 / 48(25.0 \%)$ & 0/48 (0\%) & $2 / 48$ (4.2\%) & 4/48 (8.3\%) & $5 / 48$ (10.4\%) \\
\hline & Total & 50/132 (37.9\%) & 4/132 (3.0\%) & 3/132 (2.3\%) & 7/132 (5.3\%) & 10/132 (7.6\%) \\
\hline \multirow[t]{3}{*}{ Myanmar } & Cattle & 47/125 (37.6\%) & 0/125 (0\%) & $3 / 125$ (2.4\%) & $7 / 125$ (5.6\%) & $9 / 125$ (7.2\%) \\
\hline & Buffalo & $2 / 5(40.0 \%)$ & 0/5 (0\%) & $0 / 5(0 \%)$ & $0 / 5(0 \%)$ & $0 / 5(0 \%)$ \\
\hline & Total & 49/130 (37.7\%) & 0/130 (0\%) & $3 / 130$ (2.3\%) & $7 / 130(5.4 \%)$ & $9 / 130(6.9 \%)$ \\
\hline Cattle total & & 85/209 (40.7\%) & 4/209 (1.9\%) & 4/209 (1.9\%) & $10 / 209$ (4.8\%) & 14/209 (6.7\%) \\
\hline Buffalo total & & $14 / 53$ (26.4\%) & 0/53 (0\%) & 2/53 (3.8\%) & $4 / 53(7.5 \%)$ & $5 / 53(9.4 \%)$ \\
\hline Total & & 99/262 (37.8\%) & 4/262 (1.5\%) & 6/262 (2.3\%) & 14/262 (5.3\%) & 19/262 (7.3\%) \\
\hline
\end{tabular}

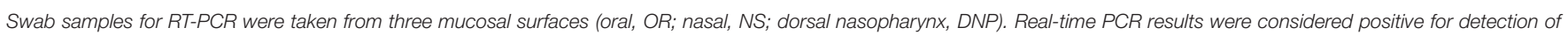
FMDV RNA at any CT value under 40.

could cause NSP-positive reactors) is thought to be low in both Laos and Myanmar, and was not considered likely to influence NSP ELISA results. In Laos, vaccination rates are thought to be as low as $18 \%$, with incomplete adherence to vaccination schedules in many cases (35). Both countires in this study had recently carried out mass vaccination campaigns (36), however these utilised purified, subunit vaccines which would not have been detected by the serology assay used here. In our study, animals with detectable mucosal viral RNA at any site were significantly more likely to be seropositive than the sampled population, but not all RNA-positive animals had antibodies. Since development of antibodies postdates initial infection and early replication, animals with detectable FMDV RNA but no antibodies might have been in the incubation phase or the early (neoteric) stages of subclinical infection (8), or may have represented false negative reactors. The FMD PrioCHECK NSP ELISA has a diagnostic specificity of $99.5 \%$ in vaccinated and $97.2 \%$ in non-vaccinated cattle, and a diagnostic sensitivity of $97.2 \%$ (37). There is some evidence that this sensitivity may further decrease in the face of natural infection. Three commercial NSP ELISAs were found to have a decreased diagnostic sensitivity of $21.6-28.4 \%$ when used on known-infected recovered cattle sera from the 2010 epidemic in Japan (38) compared to the previous findings $(97.2 \%$ diagnostic sensitivity) by Brocchi et al. (37).

Six seropositive animals had detectable viral RNA in the oral and nasal cavity. Since NSP serology is not serotype specific, one possible reason for shedding is that these animals did not have protective antibodies to the same virus that was detected by RTPCR. However, we consider it unlikely that all shedding animals were in the pre-clinical stages of FMD, and more likely (given the complete absence of lesions) that the presence of FMDV on mucosal surfaces constitutes a true subclinical state of FMD infection, either carrier phase or neoteric.

In the absence of herd or village level information on FMD clinical status, no inference can be made on a potential outbreak in the animals' original herd using group level data. Overrepresentation of disease is possible in slaughterhouse populations such as this one. For example, Vietnamese poultry smallholders were reported to increase their sales to mitigate losses associated with an outbreak (39). No lesions of any stage were observed during this study, and it is unlikely that all shedding cattle were in the pre-clinical stages of FMD. Therefore, we consider that these cattle are likely to have been sub-clinically infected with FMDV.

Outbreaks of FMD in Myanmar and Laos have been attributed to incursions of new strains of $\operatorname{FMDV}(23,24)$. Our results suggest the possibility that in addition to these virus "incursions," the endemic epidemiology of FMD could include subclinical infection and shedding within populations of apparently healthy animals. Experimental studies of viral location in chronic carrier cattle and buffalo focus heavily on nasopharyngeal virus detection $(11,21,40)$. The observation that healthy dairy cattle and buffalo shed virus in their milk $(41,42)$, raises the possibility that in endemic countries, cattle could be exposed from birth to both virus and protective maternal antibodies.

Our study supports the well-established concept that FMDV is constantly circulating at low levels among fully or partiallyresistant large ruminants in endemic regions of Southeast Asia. We used dry swabs for sampling rather than metal cuvettes used at slaughter by Anderson et al. (7); this was to prevent possible contamination between animals. One limitation of this study is that detection of FMD viral RNA is not proof of the presence of viable (infectious) FMDV. However, many studies have demonstrated the high correlation between detection of FMDV RNA and infectious virus from subclinical animals in endemic settings $(6,43)$. We suggest that future work includes confirmation of FMDV viability using virus isolation. Comparison of serotypes of FMDV and circulating antibodies might help to better understand the relationships between immunity and subclinical shedding. Furthermore, repeating this study in other regions and countries where FMDV is endemic, would help substantiate this missing piece of the FMD epidemiology puzzle in endemic regions. Sampling at the village of origin, rather than the slaughterhouse, could help to minimise mixing and the possibility of neoteric infection. With further work, the technique described here could potentially be adapted and utilised in other contexts, such as forming part of a surveillance program in countries with high vaccination coverage, wishing to monitor for subclinical shedding. 
In summary, we found that $3.4 \%$ of healthy large ruminants at slaughter had detectable FMDV RNA in their oral and/or nasal cavities. Although the viability of this viral RNA was not examined in this study, our results suggest the possibility that FMDV present on the oral and nasal mucosa of asymptomatic large ruminants could play a yet-uncharacterised role in the epidemiology of FMD in Southeast Asia.

\section{DATA AVAILABILITY STATEMENT}

The raw data supporting the conclusions of this article will be made available by the authors, without undue reservation.

\section{ETHICS STATEMENT}

Ethical review and approval was not required for the animal study because samples were obtained from dead animals at abattoirs.

\section{AUTHOR CONTRIBUTIONS}

$\mathrm{KB}, \mathrm{RB}, \mathrm{AM}, \mathrm{MA}, \mathrm{RS}, \mathrm{WR}, \mathrm{RA}, \mathrm{JA}$, and BV contributed to the conception and design of the study. KB, RB, BP, AS, CH, HW, MT, KL, SK, SP, VS, and CK contributed to logistics and operations of sample collection and fieldwork, including

\section{REFERENCES}

1. Garner MG, Fisher BS, Murray JG. Economic aspects of foot and mouth disease: perspectives of a free country, Australia. Rev Sci Tech. (2002) 21:62535. doi: 10.20506/rst.21.3.1357

2. Arzt J, Pacheco JM, Rodriguez LL. The early pathogenesis of foot-andmouth disease in cattle after aerosol inoculation: identification of the nasopharynx as the primary site of infection. Vet Pathol. (2010) 47:1048-63. doi: 10.1177/0300985810372509

3. Stenfeldt C, Eschbaumer M, Pacheco JM, Rekant SI, Rodriguez LL, Arzt J. Pathogenesis of primary foot-and-mouth disease virus infection in the nasopharynx of vaccinated and non-vaccinated cattle. PLoS ONE. (2015) 10:e0143666. doi: 10.1371/journal.pone.0143666

4. Arzt J, White WR, Thomsen BV, Brown CC. Agricultural diseases on the move early in the third millennium. Vet Pathol. (2010) 47:15-27. doi: 10.1177/0300985809354350

5. van Andel M, Jones G, Buckle K, Phiri B, McFadden A, Dacre, et al. Estimating foot-and-mouth disease (FMD) prevalence in central Myanmar: comparison of village headman and farmer disease reports with serological findings. Transboundary Emerg Dis. (2020) 67:778-91. doi: 10.1111/tbed.13397

6. Bertram MR, Delgado A, Pauszek SJ, Smoliga GR, Brito B, Stenfeldt $\mathrm{C}$, et al. Effect of vaccination on cattle subclinically infected with footand-mouth disease virus in Cameroon. Prev Vet Med. (2018) 155:1-10. doi: $10.1016 /$ j.prevetmed.2018.04.003

7. Anderson EC, Doughty WJ, Anderson J. The effect of repeated vaccination in an enzootic foot-and-mouth disease area on the incidence of virus carrier cattle. Epidemiol Infect. (1974) 73:229-35. doi: 10.1017/S0022172400024062

8. Stenfeldt C, Arzt J. The Carrier conundrum; a review of recent advances and persistent gaps regarding the carrier state of foot-and-mouth disease virus. Pathogens. (2020) 9:167. doi: 10.3390/pathogens9030167

9. Yadav S, Stenfeldt C, Branan MA, Moreno-Torres KI, Holmstrom L, Delgado, et al. Parameterization of the durations of phases of foot-and-mouth disease in cattle. Front Vet Sci. (2019) 6:263. doi: 10.3389/fvets.2019.00263

10. Garland AJ. The Inhibitory Activity of Secretions in Cattle Against Foot and Mouth Disease Virus (Doctoral dissertation, London School of Hygiene and Tropical Medicine) (1974). field-based alterations to the initial study design. AL and VM performed the laboratory analysis. KB wrote the first draft. AM, $\mathrm{RB}, \mathrm{JA}, \mathrm{EV}$, and FC-A helped write drafts of the manuscript and assisted with analysis. All authors contributed to manuscript revision, read, and approved the submitted version.

\section{FUNDING}

This research was undertaken as part of the South East Asia and China Foot-and-Mouth Disease Project (SEACFMD) supported by OIE and the New Zealand Ministry for Foreign Affairs and Trade (MFAT) and the New Zealand Ministry for Primary Industries (MPI), and by the UK Department for Environment Food and Rural Affairs (Grant No. SE1130).

\section{ACKNOWLEDGMENTS}

The authors acknowledge members of the OIE-LBVD FMD Project Team and the OIE-DLF FMD Project Team for their efforts in assisting with fieldwork and data collection, and laboratory staff at the relevant laboratories for sample processing. We are grateful to Joseph O'Keefe, Ben Phiri, and Edna Gias for their review and feedback. This research was supported by the New Zealand-funded OIE SEACFMD Control Programme.

11. Stenfeldt C, Eschbaumer M, Rekant SI, Pacheco JM, Smoliga GR, Hartwig EJ, et al. The foot-and-mouth disease carrier state divergence in cattle. J Virol. (2016) 90:6344-64. doi: 10.1128/JVI.00388-16

12. Barend M, Handel IG, Nfon CK, Sørensen K, Malirat V, Bergmann I, et al. Redefining the "carrier" state for foot-and-mouth disease from the dynamics of virus persistence in endemically affected cattle populations. Sci Rep. (2016) 6:29059. doi: 10.1038/srep29059

13. Kitching RP. Clinical variation in foot and mouth disease: cattle. Rev Sci Tech. (2002) 21:499-504. doi: 10.20506/rst.21.3.1343

14. Sutmoller P, Casas Olascoaga R. Unapparent foot and mouth disease infection (sub-clinical infections and carriers): implications for control. Rev Sci Tech. (2002) 21:519-29. doi: 10.20506/rst.21.3.1366

15. Jamal SM, Belsham GJ. Foot-and-mouth disease: past, present and future. Vet Res. (2013) 44:116. doi: 10.1186/1297-9716-44-116

16. Eldaghayes I, Dayhum A, Kammon A, Sharif M, Ferrari G, Bartels, et al. Exploiting serological data to understand the epidemiology of foot-andmouth disease virus serotypes circulating in Libya. Open Vet J. (2017) 7:1-11. doi: 10.4314/ovj.v7i1.1

17. Munsey A, Mwiine FN, Ochwo S, Velazquez-Salinas L, Ahmed Z, Maree F, et al. Spatial distribution and risk factors for foot and mouth disease virus in Uganda: opportunities for strategic surveillance. Prev Vet Med. (2019) 171:104766. doi: 10.1016/j.prevetmed.2019.104766

18. Wungak YS, Olugasa BO, Ishola OO, Lazarus DD, Ularamu GH. Footand-mouth disease (FMD) prevalence and exposure factors associated with seropositivity of cattle in north-central, Nigeria. Afr J Biotechnol. (2016) 15:1224-32. doi: 10.5897/AJB2016.15332

19. Dukpa K, Robertson ID, Ellis TM. The seroprevalence of foot-andmouth disease in the sedentary livestock herds in four districts of Bhutan. Prevent Vet Med. (2011) 100:231-6. doi: 10.1016/j.prevetmed.2011. 04.013

20. Blacksell SD, Khounsy S, Conlan JV, Gleeson LJ, Colling A, Westbury HA. Foot and mouth disease in the Lao People's Democratic Republic: II. Seroprevalence estimates, using structured surveillance and surveys of abattoirs. Rev Sci Tech. (2008) 27:851-9. doi: 10.20506/rst.27.3.1839

21. de Carvalho Ferreira HC, Pauszek SJ, Ludi A, Huston CL, Pacheco JM, Le VT, et al. An integrative analysis of foot-and-mouth disease virus carriers in 
Vietnam achieved through targeted surveillance and molecular epidemiology. Transboundary Emerg Dis. (2017) 64:547-63. doi: 10.1111/tbed.12403

22. Blacksell SD, Siengsanan-Lamont J, Kamolsiripichaiporn S, Gleeson LJ, Windsor PA. A history of FMD research and control programmes in Southeast Asia: lessons from the past informing the future. Epidemiol Infect. (2019) 147:e171. doi: 10.1017/S0950268819000578

23. Bo LL, Lwin KS, Ungvanijban S, Knowles NJ, Wadsworth J, King DP, et al. Foot-and-mouth disease outbreaks due to an exotic serotype Asia 1 virus in Myanmar in 2017. Transboundary Emerg Dis. (2019) 66:1067-72. doi: $10.1111 /$ tbed.13112

24. Khounsy S, Conlan JV, Gleeson LJ, Westbury HA, Colling A, Paton DJ, et al. Foot and mouth disease in the Lao People's Democratic Republic: I. a review of recent outbreaks and lessons from control programmes. Rev Sci Tech. (2008) 27:839-49. doi: 10.20506/rst.27.3.1840

25. van Andel M, Zaari S, Bernard P, McFadden A, Dacre I, Bingham, et al. Evaluating the utility of national-scale data to estimate the local risk of footand-mouth disease in endemic regions. Transboundary Emerg Dis. (2020) 67:108-20. doi: 10.1111/tbed.13329

26. Pacheco JM, Smoliga GR, O’Donnell V, Brito BP, Stenfeldt C, Rodriguez LL, et al. Persistent Foot-and-Mouth Disease virus infection in the nasopharynx of cattle: tissue-specific distribution and local cytokine expression. PLOS ONE. (2015) 10:e0125698. doi: 10.1371/journal.pone.0125698

27. Callahan JD, Brown F, Osorio FA, Sur JH, Kramer E, Long GW, et al. Use of a portable real-time reverse transcriptase-polymerase chain reaction assay for rapid detection of foot-and-mouth disease virus. J Am Vet Med Assoc. (2002) 220:1636-42. doi: 10.2460/javma.2002.220.1636

28. R Core Team. R: A Language and Environment for Statistical Computing. Vienna, Austria: R Foundation for Statistical Computing (2014). http://www. R-project.org/.

29. Farooq U, Ahmed Z, Naeem K, Bertram M, Brito B, Stenfeldt, et al. Characterization of naturally occurring, new and persistent subclinical footand-mouth disease virus infection in vaccinated Asian buffalo in Islamabad Capital Territory, Pakistan. Transbound Emerg Dis. (2018) 65:1836-50. doi: 10.1111/tbed.12963

30. Navid MT, Farooq U, Latif A, Awais MM, Anwar MI, Akhtar M, et al. Prevalence of foot and mouth disease virus in apparently healthy buffaloes brought to Islamabad slaughterhouse in Pakistan. Trop Biomed. (2018) 35:161-7.

31. Reid SM, Ebert K, Bachanek-Bankowska K, Batten C, Sanders A, Wright C, et al. Performance of real-time reverse transcription polymerase chain reaction for the detection of foot-and-mouth disease virus during field outbreaks in the United Kingdom in 2007. J Vet Diagn Invest. (2009) 21:32130. doi: $10.1177 / 104063870902100303$

32. King DP, Ferris NP, Shaw AE, Reid SM, Hutchings GH, Giuffre AC, et al. Detection of foot-and-mouth disease virus: comparative diagnostic sensitivity of two independent real-time reverse transcription-polymerase chain reaction assays. J Vet Diagn Invest. (2006) 18:93-7. doi: 10.1177/1040638706018 00114

33. Stenfeldt C, Lohse L, Belsham GJ. The comparative utility of oral swabs and probang samples for detection of foot-and-mouth disease virus infection in cattle and pigs. Vet microbiol. (2013) 162:330-7. doi: 10.1016/j.vetmic.2012.09.008

34. Parthiban ABR, Mahapatra M, Gubbins S, Parida S. Virus excretion from footand-mouth disease virus carrier cattle and their potential role in causing new outbreaks. PLoS ONE. (2015) 10:e0128815. doi: 10.1371/journal.pone.0128815
35. Xaydalasouk K, Innoula N, Putthana V, Chanthavongsa K, Snoeck CJ, Hübschen JM, et al. High seroprevalence of Foot and Mouth Disease in Laos: Call for nationwide vaccination campaigns and disease surveillance. Transboundary Emerg Dis. (2020) 1-8. doi: 10.1111/tbed.13895

36. Mcfadden A, Rawdon TG, Poulin A, Abila R, Dacre I, Sutar A, et al. Biosecurity in endemic foot and mouth disease settings: a case study of foot and mouth disease vaccination in South-East Asia. Rev Sci Tech. (2020) 38:681-94. doi: 10.20506/rst.38.3.3017

37. Brocchi E, Bergmann I, Dekker A, Paton D, Sammin D, Greiner M, et al. Comparative evaluation of six ELISAs for the detection of antibodies to the non-structural proteins of foot-and-mouth disease virus. Vaccine. (2006) 24:6966-79. doi: 10.1016/j.vaccine.2006.04.050

38. Fukai K, Morioka K, Onozato H, Yoshida K, Sakamoto K. Comparative evaluation of three commercial ELISA kits for detection of antibodies to a nonstructural protein of foot-and-mouth disease virus. J Vet Med Sci. (2012) 12-0430. doi: 10.1292/jvms.12-0430

39. Delabouglise A, Thanh NTL, Xuyen HTA, Nguyen-Van-Yen B, Tuyet PN, Lam, et al. Poultry farmer response to disease outbreaks in smallholder farming systems in southern Vietnam. eLife. (2020) 9:e59212. doi: 10.7554/eLife.59212

40. Moonen P, Jacobs L, Crienen A, Dekker A. Detection of carriers of footand-mouth disease virus among vaccinated cattle. Vet Microbiol. (2004) 103:151-60. doi: 10.1016/j.vetmic.2004.07.005

41. Ahmed H, Farooq U, Zahur AB, Naeem K, Latif A, Irshad H. Evidence of foot-and-mouth disease virus excretion in the milk of apparently healthy vaccinated buffaloes in Islamabad, Pakistan. Turk J Vet Anim Sci. (2017) 41:431-4. doi: 10.3906/vet-1512-96

42. Nawaz Z, Siddique AB, Zahoor MA, Aslam B, Zahoor MK, Ali S, et al. Detection of foot and mouth disease virus shedding in milk of apparently healthy buffaloes and cattle of Punjab, Pakistan. Buffalo Bull. (2019) 38:255-61.

43. Biswal JK, Ranjan R, Subramaniam S, Mohapatra JK, Patidar S, Sharma MK, et al. Genetic and antigenic variation of foot-and-mouth disease virus during persistent infection in naturally infected cattle and Asian buffalo in India. PLoS ONE. (2019) 14:6e0214832. doi: 10.1371/journal.pone.0214832

Conflict of Interest: The authors declare that the research was conducted in the absence of any commercial or financial relationships that could be construed as a potential conflict of interest.

Publisher's Note: All claims expressed in this article are solely those of the authors and do not necessarily represent those of their affiliated organizations, or those of the publisher, the editors and the reviewers. Any product that may be evaluated in this article, or claim that may be made by its manufacturer, is not guaranteed or endorsed by the publisher.

Copyright $\odot 2021$ Buckle, Bueno, McFadden, van Andel, Spence, Hamill, Roe, Vallee, Castillo-Alcala, Abila, Verin, Purevsuren, Sutar, Win, Thiha, Lwin, Khounsy, Phonthasy, Souriya, Keokhamphet, Arzt, Ludi and Mioulet. This is an open-access article distributed under the terms of the Creative Commons Attribution License (CC $B Y)$. The use, distribution or reproduction in other forums is permitted, provided the original author(s) and the copyright owner(s) are credited and that the original publication in this journal is cited, in accordance with accepted academic practice. No use, distribution or reproduction is permitted which does not comply with these terms. 